\title{
Юбилей химического факультета МГУ увенчал Международный год Периодической таблицы химических элементов
}

\section{С. В. Ивашко,}

МГУ им. М.В. Ломоносова

ivashkos@yandex.ru

\begin{abstract}
28 ноября 2019 года в Фундаментальной библиотеке МГУ состоялась Торжественная церемония, посвященная закрытию в России Международного года Периодической таблицы химических элементов и 90-летию химического факультета Мгу.

2019 год провозглашен Генеральной ассамблеей ООН Международным годом Периодической таблицы химических элементов. Это масштабное событие посвящено 150-летию открытия Периодического закона химических элементов великим русским ученым Д. И. Менделеевым. Торжественные мероприятия совмещены с празднованием юбилея химического факультета МГУ, так как это ведущий химический научнообразовательный центр России, неразрывно связанный с развитием химии, а также один из ключевых организаторов всех мероприятий в честь Года Таблицы.
\end{abstract}

Участниками и гостями Церемонии закрытия Международного года Периодической таблицы в России стали более 1500 человек из различных регионов России и других стран мира. Среди гостей вечера выдающиеся ученые-химики, политики, ректоры ведущих химических университетов и директора академических институтов, руководители крупнейших российских компаний химической, фармацевтической и IT-индустрии. Также в числе приглашенныхОлимпийская сборная России по химии, которая традиционно тренируется к предстоящим соревнованиям на химическом факультете МГУ.

В торжественной церемонии закрытия Международного года в России приняли участие
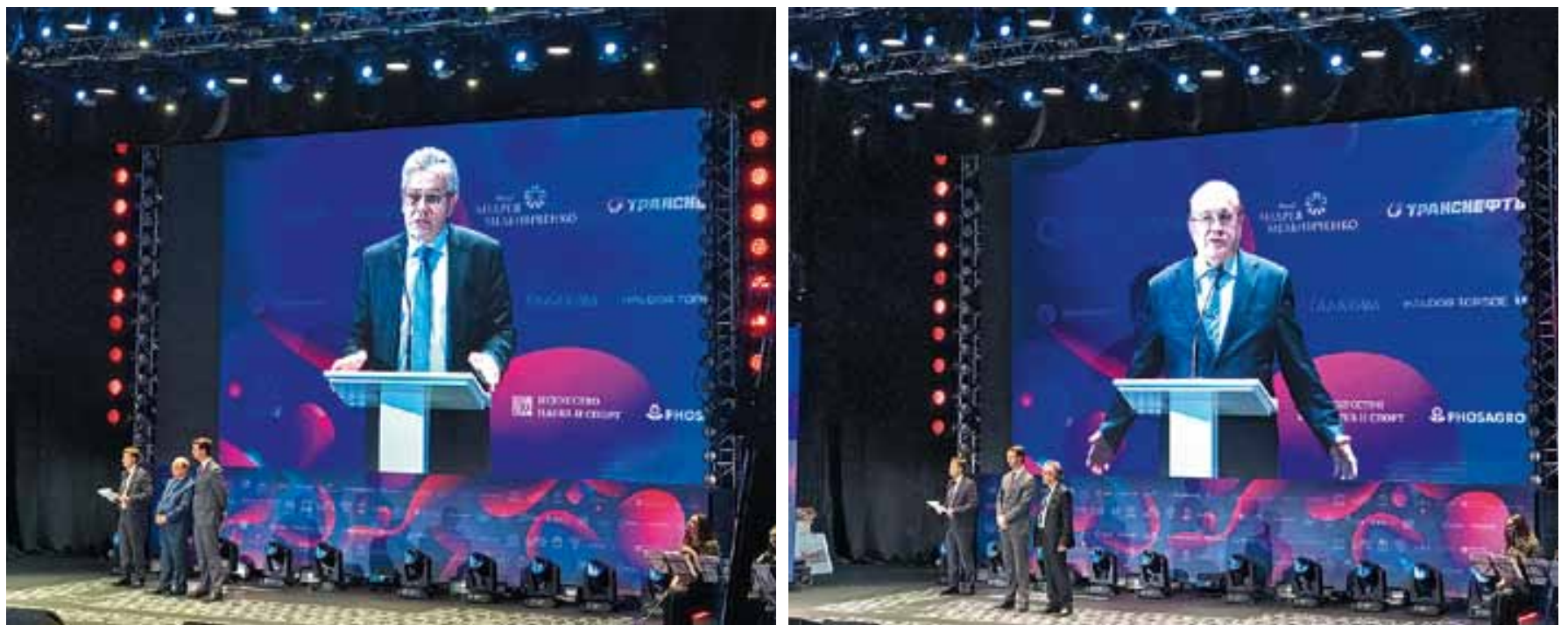

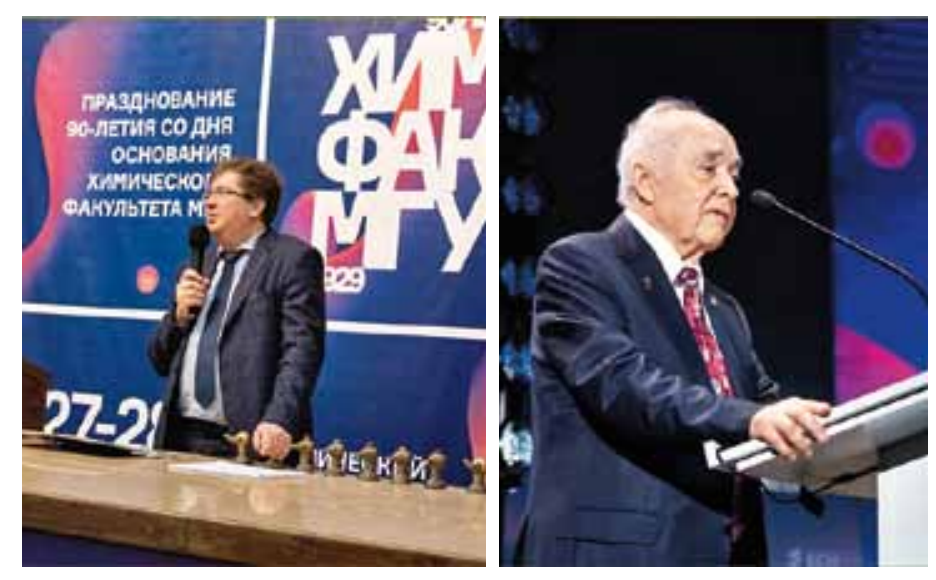

заместитель министра науки и высшего образования РФ Григорий Трубников, ректор МГУ академик Виктор Садовничий, президент РАН академик Александр Сергеев и другие представители научной общественности.

Заместитель министра науки и высшего образования РФ Григорий Трубников в своем выступлении отметил: "Старт череды мероприятий в рам' ках Международного года Периодической таблицы химических элементов состоялся в январе в Париже, на генеральной ассамблее ЮНЕСКО, а затем на площадке РАН при участии премьер-министра РФ Дмитрия Медведева. Празднование 150-летия со дня открытия Д. И. Менделеевым Периодического закона дало колоссальный импульс для представления на мировой арене научного потенциала России, демонстрации наших достижений, современных разработок и актуальных результатов исследований. Было проведено огромное количество химических конгрессов, а выставка, посвященная Международному году

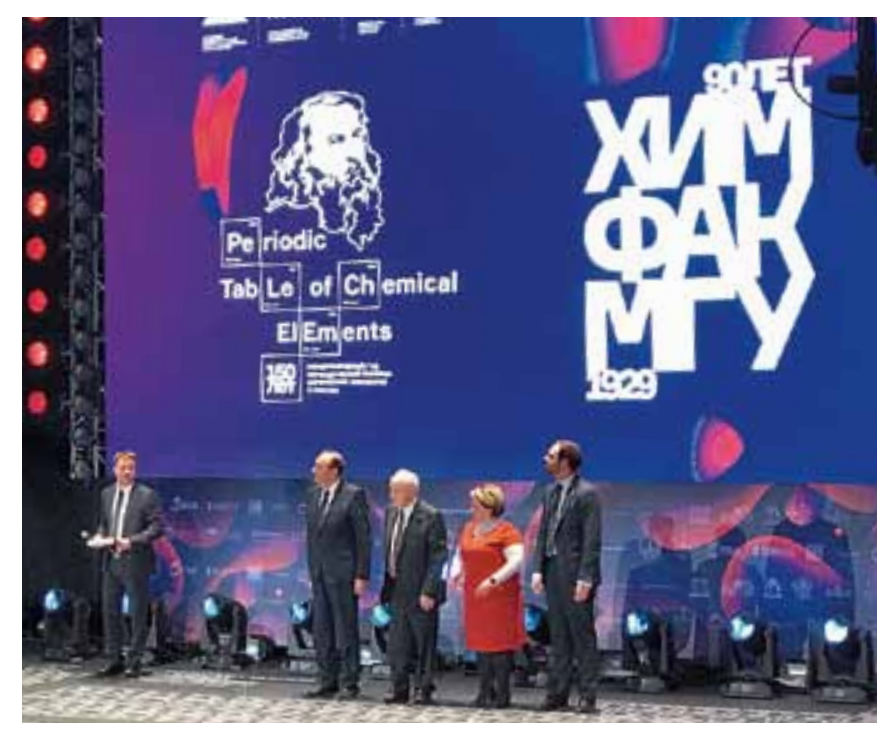

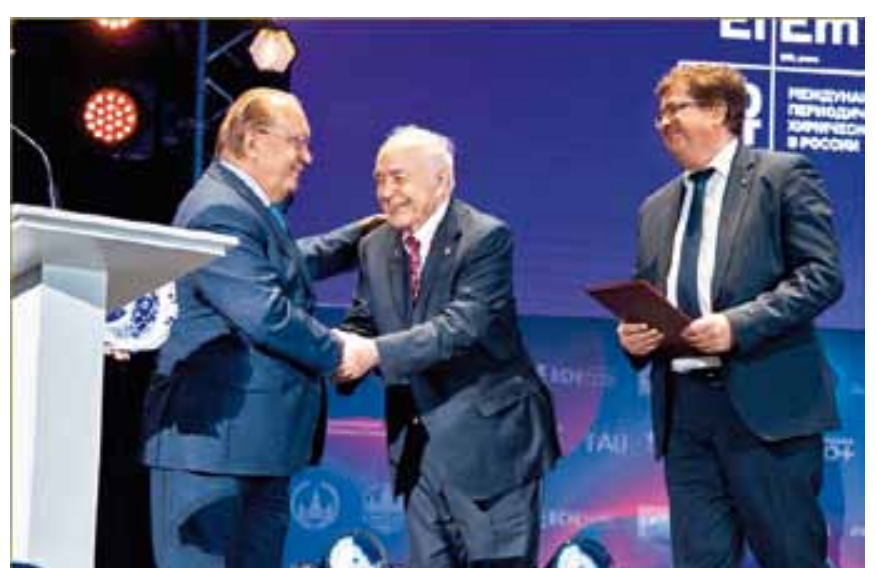

Таблицы, состоялась на Петербургском и Восточном международных экономических форумах, саммите Россия-Африка в Сочи. Большое значение имеет учреждение Международной премии ЮНЕСКО им. Д. И. Менделеева за достижения в области фундаментальных наук. Все это, безусловно, способствует укреплению престижа и популяризации отечественной науки".

С приветственным словом выступил Ректор МГу академик Виктор Садовничий: “Мы - ученые, и нам всегда интересно, как фундаментальная наука позволяет двигать вперед на целые столетия развитие общества, экономики и других сфер. Все зависит от тех озарений и тех результатов исследований, которые сделали ученые. Так и Дмитрий Менделеев: он читал в университете курс по общей химии, писал учебник и думал над тем, как упорядочить информацию. Таким образом родилась идея - Периодический закон химических элементов. Менделеев, безусловно, гений, ученый, имя которого знают во всем мире.

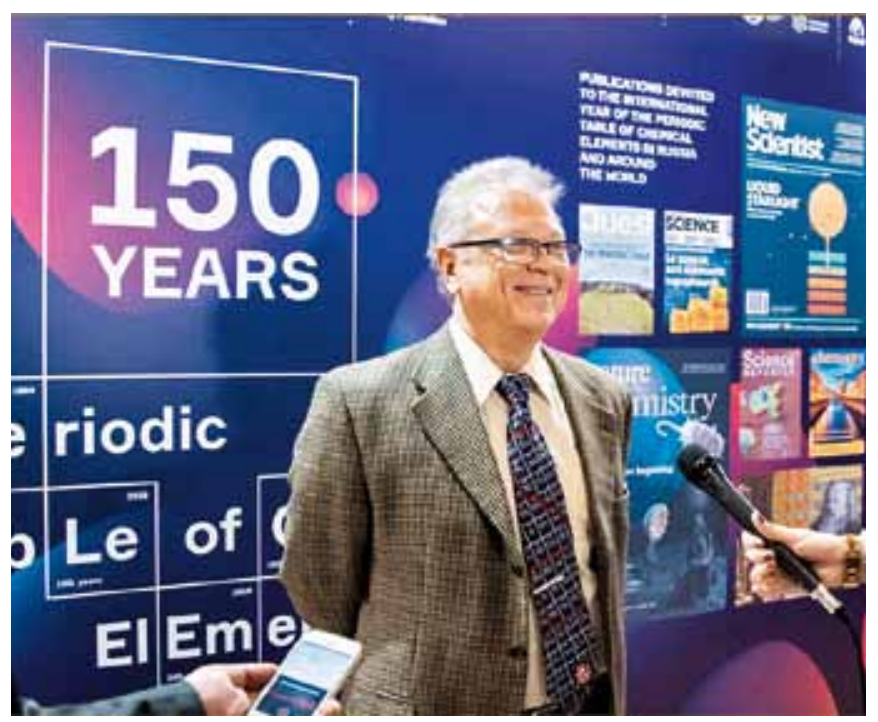




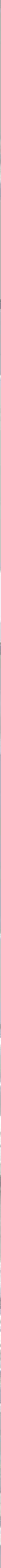


И я очень рад, что этот год мы посвятили празднованию 150-летия его открытия".

В свою очередь, президент РАН академик Александр Сергеев добавил: "Мы плодотворно провели Год Периодической таблицы. В первую очередь, мы учредили вместе с ЮНЕСКО престижную премию им. Д. И. Менделеева - и это очень важный результат этого года. Таким образом, мы утвердили имя Менделеева, имя России среди престижных мировых премий. Во-вторых, мы достойно выступили на Олимпиаде по химии в Париже. В-третьих, были близки к победе Нобелевской премии по химии. Но главный результат этого года - мы разбудили любопытство: через открытые уроки, конференции, фестивали, мы разбудили любопытство сотен тысяч людей. Любопытство не только в отношении Таблицы химических элементов, а в отношении того, насколько много значат химические элементы в нашей жизни. Получив такой толчок к познанию сегодняшнего мира и наук, мы можем быть уверены, что через несколько лет, та любознательность и толчок, который дал ей Год Таблицы Менделеева, приведет много молодежи в науку, отразится в новых открытиях".

Решение объявить 2019 год Международным годом Периодической таблицы химических элементов было принято 20 декабря 2017 года Генеральной ассамблей Организации Объединенных Наций. С инициативой выступили Российское химическое общество им. Д. И. Менделеева, Российская академия наук, Министерство науки и высшего образования РФ, российские и зарубежные ученые. Инициативу поддержали более 70 национальных и международных химических и астрофизических обществ.

Международный год Периодической таблицы химических элементов проходил под эгидой ЮНЕСКО в нескольких странах мира - России, Франции, Германии, Испании, США и Японии. В рамках этого события по всему миру были проведены тысячи мероприятий: научных конференций, тематических выставок, конкурсов молодых ученых. Открытие Международного года состоялось в Париже, церемония закрытия прошла в Токио 5 декабря 2019 года. В России Оргкомитет по подготовке Международного года Периодической таблицы химических элементов возглавил Председатель Правительства РФ Дмитрий Медведев. Премьер-министр лично участвовал в церемонии открытия Года в России, а также принял участие в работе XXI Менделеевского съезда по общей и прикладной химии .

Всего в стране прошло более 500 научнопопулярных и образовательных мероприятий, посвященных 150-летию Таблицы Менделеева и направленных на привлечение внимания школьников, студентов и молодежи к науке. Среди наиболее ярких Всероссийский Фестиваль NAUKA 0+, Всероссийский съезд учителей химии, Всероссийский открытый урок по химии, Всероссийский химический диктант, XXIX Менделеевская школа-конференция молодых ученых в Иваново, презентации дизайнерских коллекций одежды, химические турниры ученых и многое другое.

Особенно масштабной и зрелищной стала интерактивная выставка, посвященная химии и ее современным достижениям, которая в течение всего года путешествовала по стране и миру. Лучшие экспонаты этой выставки были представлены в рамках церемонии закрытия Международного года Периодической таблицы в России. Так, в холле Фундаментальной библиотеки МГУ развернулась экспозиция, где в увлекательной форме были продемонстрированы достижения ведущих российских научно-исследовательских институтов в сфере химии и материаловедения - уникальная установка по очистке воды и аэрогели от РХТУ им. Д. И. Менделеева, макеты циклотрона ДЦ-280 от Объединенного Института Ядерных Исследований
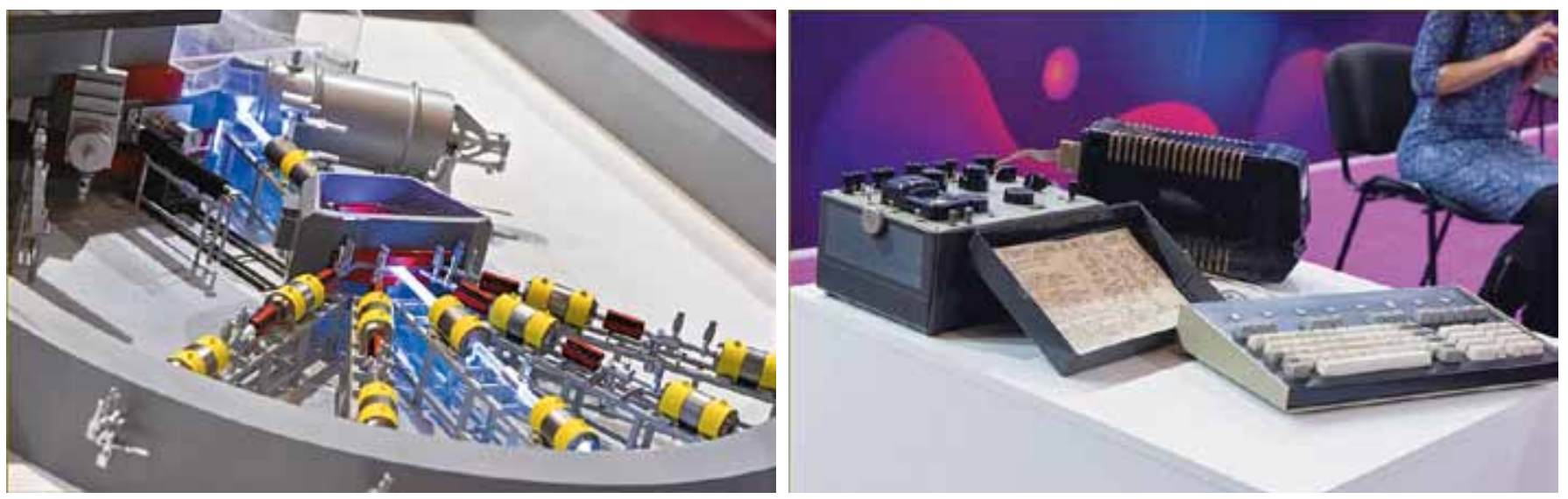

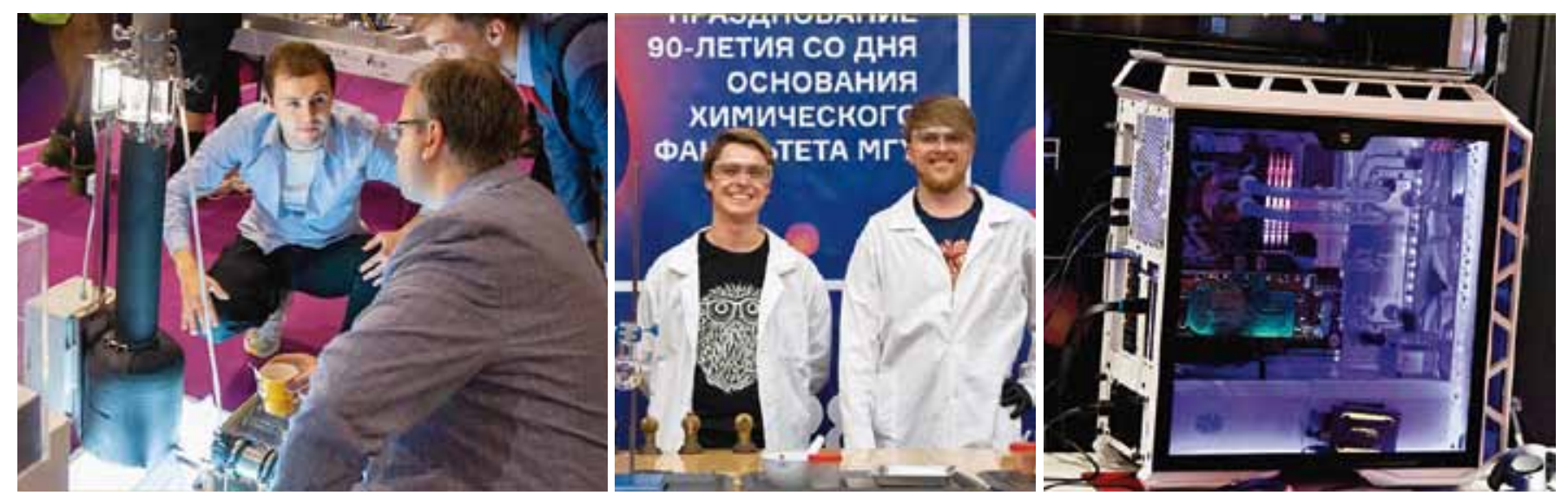

и генератора технеция от НИФХИ им. Л. Я. Карпова, а также сама Периодическая таблица химических элементов.

Кроме того, посетители исторической зоны выставки смогли сделать сэлфи с Д. И. Менделеевым в химической лаборатории 19 века, выпить в молекулярном баре коктейль "Пина Коллайдер", а также узнать с помощью VR о цветной химии и экспериментах.

Как подчеркнул ректор МГУ академик РАН Виктор Садовничий: "Химический факультет МГУ - это гордость университета. Я как ректор люблю химический факультет, потому что он спокойный, сильный, целеустремленный. Этот факультет дал миру, науке очень много известных ученых. Он дал много тех людей, которые, будучи выпускниками МГУ, остались патриотами своего любимого университета. Именно благодаря этому нам удалось создать такую мощную „оболочку“ вокруг химического факультета, огромную поддержку. И я искренне радуюсь этому юбилею!»

В свою очередь, президент химического факультета МГУ академик РАН Валерий Лунин отметил: "2019 год - это выдающееся событие в жизни химического сообщества, и в жизни всего мирового научного сообщества. Это удивительный случай, когда накануне Генеральная ассамблея ООН практически единогласно проголосовала за объявление 2019 года годом 150-летия Периодической таблицы Менделеева, в честь чего 29-30 января состоялась церемония открытия в Париже, накануне дня рождения Менделеева. Это великое событие, которого стоило ждать 150 лет И, безусловно, оно вдохновило тысячи и миллионы людей проявить интерес к химической науке".

Значительную часть экспозиции составили инновационные проекты химического факультета Мгу, многие из которых были представлены впервые. Среди новых актуальных разработок химиков МГу проточный аккумулятор для хранения и переработки энергии, экспресс-тест для определения вируса гриппа, персональное лекарство, распечатанное на принтере, натрий-ионные аккумуляторы и многое другое. Экспозицию дополнили проекты российских химических, фармацевтических и IT-компаний.

По словам декана химического факультета МГУ чл.-корр. РАН Степана Калмыкова, "химфак сегодня это 3,5 тысячи людей: студентов, аспирантов, преподавателей, ученых; это отдельные корпуса, сложная структура, множество проектов. Но в первую очередь, это философия, образ жизни, которые большинство работающих здесь людей хорошо понимают и разделяют. 90 лет - это еще не так много, и у нас все впереди. У нас много планов, как сделать наш университет и нашу страну еще лучше".

Официальным оператором проведения Международного года Периодической таблицы химических элементов в России выступил Всероссийский фестиваль науки NAUKA 0+. Генеральный партнер Международного года Периодической таблицы химических элементов в России - Благотворительный Фонд "Искусство, наука и спорт".

В организации юбилейных торжеств также сыграли серьезную роль компании, созданные выпускниками химического факультета, друзья и партнеры факультета, особенно ООО "Натива" и Группа ЕСH, а также компании "Август", "Биохиммак", Qiwi, "Транснефть", "Уралкалий", "Унихимтек", Фонд Андрея Мельниченко. Также помощь оказали компании "Пробиотец", "Унитех", "Галахим", Halror Topsoe.

Проведение Международного года Периодической таблицы химических элементов имеет особое значение для России, так как способствует международному признанию заслуг великого русского ученого Д. И. Менделеева, а также укреплению престижа и популяризации отечественной науки.

5 декабря 2019 года в Токио прошла Церемония закрытия Международного года Периодической таблицы Дмитрия Ивановича Менделеева. 
16-я Международная специализированная выставка МИР КЛИМАТА 2020

Системы кондиционирования и вентиляции, отопление, промышленный и коммерческий холод

\section{$\approx$ \\ MИP Aill

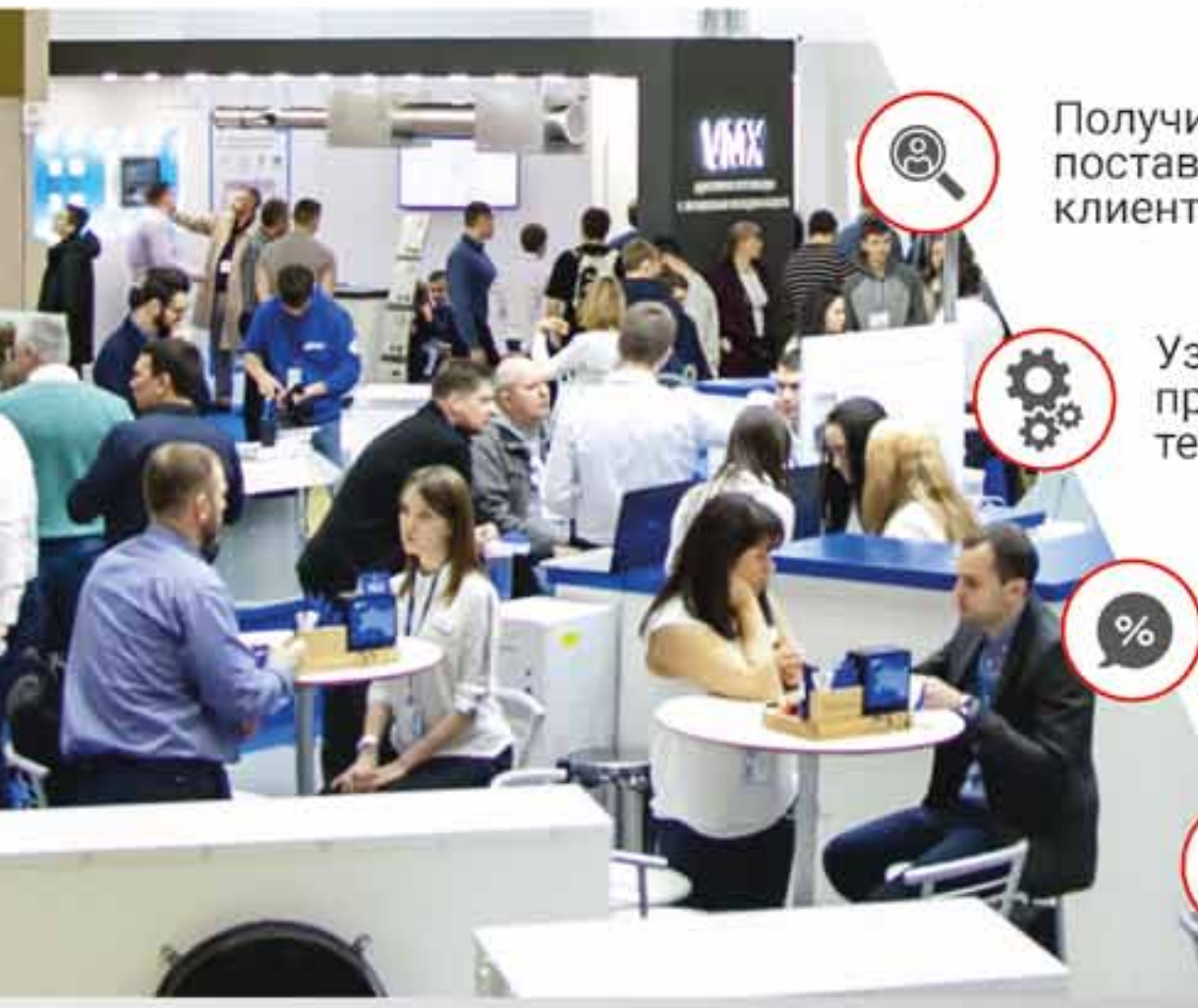

Договориться о

выгодных условиях

и скидках

МОНТАЖ КОНДИЦИОНЕРОВ ТВОЙ БИЗНЕС?

ВЫСТАВКА ПОМОЖЕТ ЗАРАБОТАТЬ

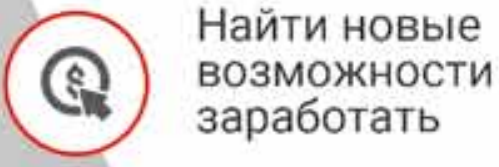

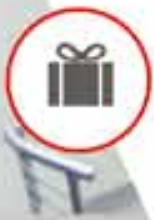

Выиграть ценные подарки
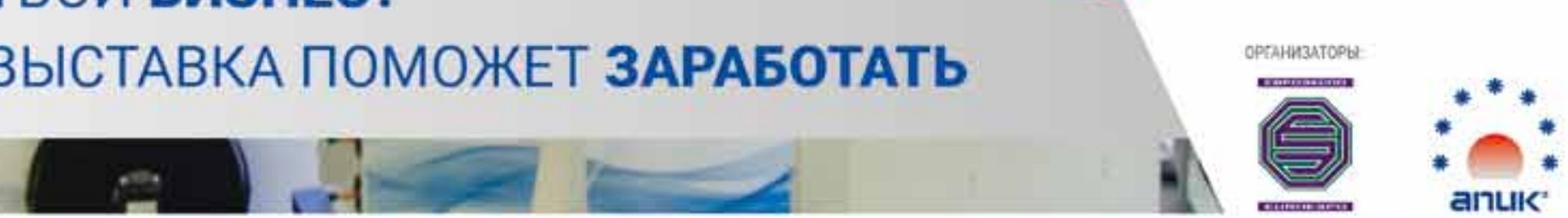

Регистрируйся по специальному промокоду CLIMATE и получай

предложения от участников выставки
Buhler-AHS

COOLAUTOMATION A

BellunGミ

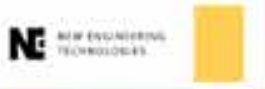

Посетите стенд компании Buhler-AHS, заполните анкету и выиграйте монтаж системы увлажнения воздуха:

Предоставление дополнительной скидки

$5 \%$ на контроллер CoolMasterNet

Скидка $18 \%$ на универсаліьные инверторные холодильные сплит-системы Belluna. Феноменальная энергозффективность. Нет аналогов России!

Скидка 15\% на инструмент дия соединения листового материала $6 е з$ применения заклепок, за счет пластической деформации мегапла

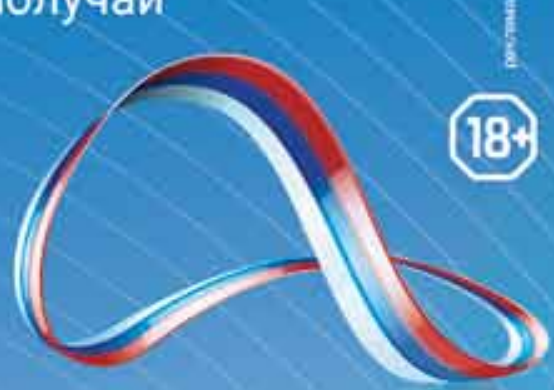

TBOAEECHIATHLS вила:

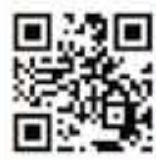

Turbō]et 